\title{
Dielectric Properties of Nanocomposites based on Epoxy Resins and Titanium Dioxide
}

\author{
A. G. Getmanov', Tran Quyet Thang ${ }^{2}$, \\ ${ }^{1}$ Moscow Aviation Institute (National Research University), \\ Moscow, Volokolamskoe shosse, 4, 125993, \\ Russia \\ ${ }^{2}$ Le Quy Don Technical University \\ Hanoi, 236 Hoang Quoc Viet, \\ Vietnam
}

Received: March 31, 2021. Revised: August 26, 2021. Accepted: September 10, 2021. Published: September 13, 2021.

\begin{abstract}
In this work, polymer composite materials based on nanoparticles of titanium dioxide and epoxy polymer have been obtained. The dielectric properties of the obtained composite are investigated. Studies have shown that the introduction of $\mathrm{TiO}_{2}$ nanoparticles into an epoxy polymer leads not only to a slowdown in relaxation processes, but also increases the value of the through conduction. It was shown that the greatest influence of the introduction of nanoparticles on relaxation processes is observed on the $\alpha$-relaxation.
\end{abstract}

Keywords-Composites, resins, titanium dioxide, conductivity.

\section{INTRODUCTION}

$\mathrm{H}$ IGH-PERFORMANCE polymer composite materials are now finding more and more applications in our daily life [1][18]. A composite is usually a combination of a matrix and a filler; in the case of nanocomposites, the filler is nano-sized along one of the measurement axes [19]-[35].

Modern composites have not only a wide range of physical and mechanical properties, but are also capable of directionally changing them, for example, increasing fracture toughness, regulating rigidity, strength, and other properties. These possibilities are expanded when fibers of different nature and geometry are used in composites, i.e., when creating hybrid composites. In addition, these materials are characterized by the appearance of a synergistic effect (coordinated joint action of several factors in one direction).

The properties of the interface or interfacial zone, first of all, the adhesive interaction between the fiber and the matrix, determine the level of properties of composites and their retention during operation. Local stresses in the composite reach their maximum values just near or directly at the interface, where material destruction usually begins. The interface must have certain properties to ensure efficient transfer of the mechanical load from the matrix to the fiber. The adhesion bond at the interface should not be destroyed under the action of thermal and shrinkage stresses arising from the difference in the temperature coefficients of linear expansion of the matrix and fiber or as a result of chemical shrinkage of the binder during its curing.

When creating nanocomposites, the key tasks are the development of efficient, reliable, and affordable production technologies for mass production, which make it possible to obtain materials with stable characteristics. The hand lay technique, also called wet lay, is the simplest and most widely used process for producing flat reinforced composites. The process consists of laying layers of a polymer in successive layering using an epoxy matrix. Wet-laying is a molding process that combines layers of reinforced carbon fiber with epoxy to create a high-quality laminate. Before starting the installation process, you must prepare the appropriate form. This preparation consists of cleaning the table and applying a release agent to the surface. The manual laying process can be divided into four main steps: mold preparation, epoxy coating, laying and curing. Form preparation is one of the most important steps in the installation process. This process requires dry reinforcement layers and the application of a wet epoxy matrix. They are connected together - reinforcing material, impregnated with a matrix - epoxy resin.

Titanium dioxide is one of the promising materials as a nanofiller due to its optical, thermal, photocatalytic and electrophysical properties. The application potential of nanodispersed $\mathrm{TiO}_{2}$ is very high: titanium dioxide and 
materials based on it can be used as an additive in plastics, an ultraviolet light blocker, an energy converter in solar batteries, an agent for photocatalytic degradation of bacteria and photochemical degradation of toxic chemicals, for wastewater treatment. Due to their chemical inertness, low toxicity, photocatalytic activity, high refractive index and other beneficial properties, titanium dioxide $\left(\mathrm{TiO}_{2}\right)$ nanoparticles have attracted the attention of many researchers and are used in the food, paint and varnish industry, etc. Previous studies have shown that the introduction of $\mathrm{TiO}_{2}$ nanoparticles improves some properties of epoxy resin. But the process of interaction and the mechanism of hardening of epoxy resin are not fully understood [44]-[52]. There are few works on epoxy nanocomposites with $\mathrm{TiO}_{2}$ nanoparticles; therefore, it is relevant to obtain new examples of such nanocomposites and study their physical and mechanical properties, since due to the presence of $\mathrm{TiO}_{2}$, it is possible to use such nanocomposites in biomedicine, as bactericidal and photocatalytic surfaces. The aim of this work is to create an epoxy nanocomposite based on $\mathrm{TiO}_{2}$ nanoparticles and to study its physical and mechanical properties depending on the concentration of nanoparticles.

The matrix can be a thermosetting polymer - epoxy resin, which has already found many applications: from structural composites to adhesives and surface coatings. Epoxy resins already have a number of unique qualities among polymers: no shrinkage during curing, high adhesion to various substrates, good dielectric and other valuable properties [36]-[44]. Nanocomposites using thermoplastic polymers are well known and studied to improve mechanical, electrical, thermal and insulating properties [45]-[78]. However, nanocomposites using thermosetting polymers have not been studied as widely, especially using $\mathrm{TiO}_{2}$. The aim of this study was to investigate the dielectric properties of nanocomposites based on epoxy resin and titanium dioxide nanoparticles in view of their potential application as construction and functional materials.

\section{NUMERICAL CALCULATIONS OF THE DIELECTRIC PROPERTIES OF POLYMER NANOCOMPOSITES}

To identify the elastic properties of a monolayer from the known values of the elastic moduli of composite samples with different reinforcement schemes, we will use the classical model of layered composites.

An analytical calculation to determine the effective elastic properties of a monolayer will be carried out in the DigimatMF module using the Mori-Tanaka averaging method. Separately, we will also evaluate the effect of the filler on the elastic modulus of the matrix, considering the material containing only nanoparticles as inclusions. Based on these calculations, we will determine the "effective" volumetric content of inclusions, taking into account the influence of interphase layers formed around the inclusions. The influence of these layers, as will be shown below, cannot be neglected, since in this case underestimated values of the elastic characteristics of the matrix will be obtained. Therefore, in fact, knowing the modulus of elasticity of the nanomodified matrix from experiments, the content of the filler will be selected such that the calculation and experiment will coincide. The found value of the effective volumetric content of inclusions is further used in analytical and numerical calculations of the properties of a monolayer.

Numerical calculations will be carried out using the Digimat-FE module. The size of a cubic representative fragment was set by the system automatically. The effective elastic properties were calculated by determining the ratio of the volume-averaged representative fragment of the stress level to a given value of homogeneous deformations. In this case, the boundary conditions and the geometry of the fragment itself are periodic. The calculations were carried out using the finite element method.

Nanoparticles, even with a very low volumetric content (less than $1 \%$ ), are contained in such a fragment in a very large amount, and it is impossible to model their effect at this scale level. For example, a cubic fragment of a $1 \mu \mathrm{m}$ matrix contains more than thousand nanoparticles for a given volumetric content. Therefore, in particular, the nano-modified binder is white, while the usual binder is yellow. To model such materials, it is necessary to resort to multiscale approaches and to carry out a consistent determination of effective properties at various scale levels. This task is greatly simplified if the properties of the nanomodified matrix are known from experiments. In particular, it is known that its Young's modulus is $2.5 \mathrm{GPa}$. The missing characteristic is Poisson's ratio, which can be approximately taken unchanged, or estimated on the basis of analytical calculations using the found value of the "effective" volumetric content of the filler, which was done. Further, it suffices to numerically solve the averaging problem on a representative fragment containing only nanoparticles.

To obtain an analytical assessment of the properties of the nanomodified sample, the "effective" volumetric content of nanoparticles in the matrix was preliminarily determined, at which the calculated value of the effective Young's modulus of the nanomodified matrix coincides with the known experimental value $(2,5 \mathrm{GPa})$. It was found that if we do not take into account interfacial effects, then the calculation predicts the effective Young's modulus equal to 2,04 GPa, with an initial value of $2 \mathrm{GPa}$. That is, with such a low content $(1 \%)$ of even very hard inclusions, they should not have a significant effect on the properties of the material. The experimentally found increase in the matrix modulus can be explained by the influence of hardened and rigid interphase zones formed around the inclusions. For an approximate assessment of their influence, the concept of "effective" volumetric content of inclusions is introduced. It is assumed that the properties of the interphase zones and inclusions are the same, and the calculation should use the value of the "effective" volumetric content of inclusions, which is the sum of their real volumetric content and the content of interfacial zones. This value was approximately $10 \%$ for the considered composite. In this case, 
the predicted Young's modulus of the modified matrix is 2,5 $\mathrm{GPa}$, Poisson's ratio is 0,39 , and the thermal expansion coefficient is $5,76 \cdot 10^{-5}$.

Based on the results of experimental studies, the effective characteristics of a monolayer made of a composite material based on both conventional and nanomodified matrices were determined, and a solution to the corresponding inverse problem was obtained. It was found that the addition of nanoparticles within the recommended standard range of $10 \%$ leads to a slight increase in the longitudinal elastic modulus and shear modulus of the monolayer. In this case, there is an almost twofold decrease in the elastic modulus in the transverse direction and a decrease to zero Poisson's ratio. The reliability of the developed numerical models is confirmed by a good correlation between the results of both numerical and analytical solutions and the obtained experimental data on the study of the thermomechanical characteristics of nanomodified materials.

The effect of $\mathrm{TiO}_{2}$ nanoparticles with concentrations from 0 to $3 \%$ by weight on the electrical conductivity and dielectric characteristics of the epoxy polymer in a wide range of frequencies and temperatures was studied.

The image (Figure 1) shows the dependence of the

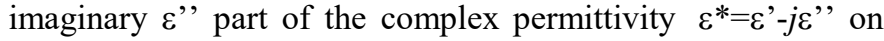
the frequency and temperature in the original polymer film.

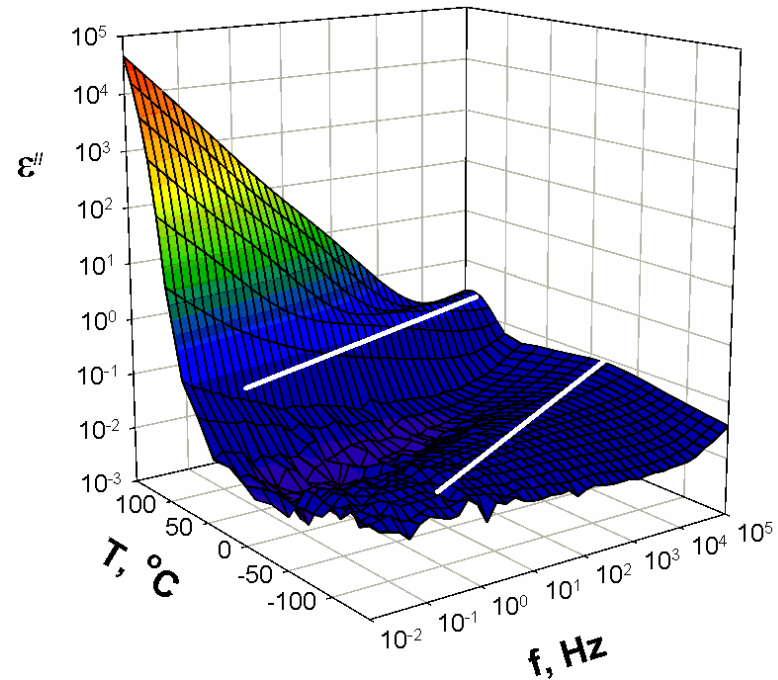

Fig. 1 Dependence of $\varepsilon$ ' on frequency and temperature in epoxy resin.

It can be seen from the figure that a complex relaxation pattern is observed in the measured range of frequencies and temperatures, due to comparable contributions to $\varepsilon^{*}$ of electric dipole relaxation and electrical conductivity $\sigma^{*}=\sigma^{\prime}+j \sigma^{\prime \prime}\left(\sigma^{\prime}\right.$ - is real, $\sigma "$ - the imaginary part of the specific complex conductivity) (observed at high temperatures). There are two main relaxation peaks. Both peaks shift to higher frequencies with increasing temperature. The image (Figure 2) shows the dependence of the low-temperature relaxation peak P1 for different contents of $\mathrm{TiO}_{2}$ nanoparticles in the epoxy oligomer. It can be seen that, upon the addition of nanoparticles with a concentration of $3 \%$ by weight, a shift of the peak towards lower frequencies is observed.

\section{RESULTS OF THE EXPERIMENTAL STUDY OF DIELECTRIC PROPERTIES OF POLYMER NANOCOMPOSITES}

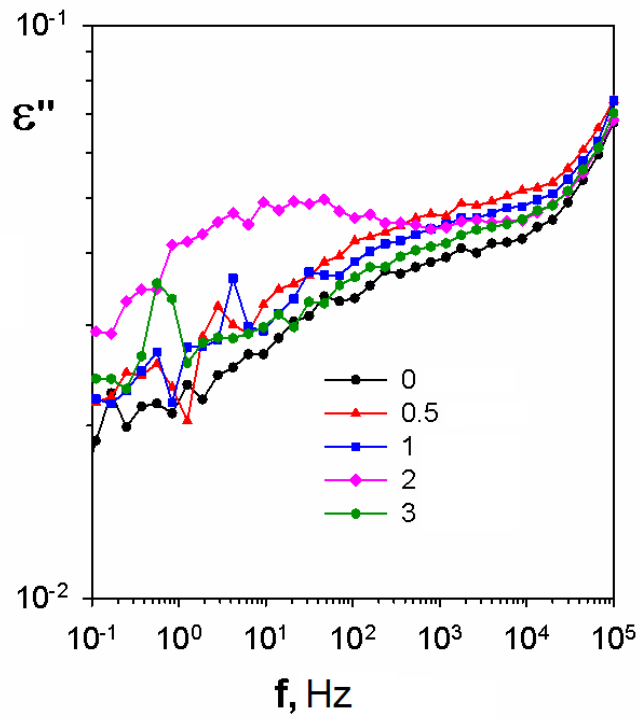

Fig. 2 Dependence of $\varepsilon$ ', on frequency in an epoxy polymer containing different concentrations of $\mathrm{TiO}_{2}$ nanoparticles (wt.\%). Measurement temperature $-60{ }^{\circ} \mathrm{C}$.

The second relaxation peak P2 (Figure 3) is observed at higher temperatures. It can be seen that a shift of the relaxation peak towards lower frequencies is also observed for different contents of $\mathrm{TiO}_{2}$ nanoparticles in the epoxy polymer.

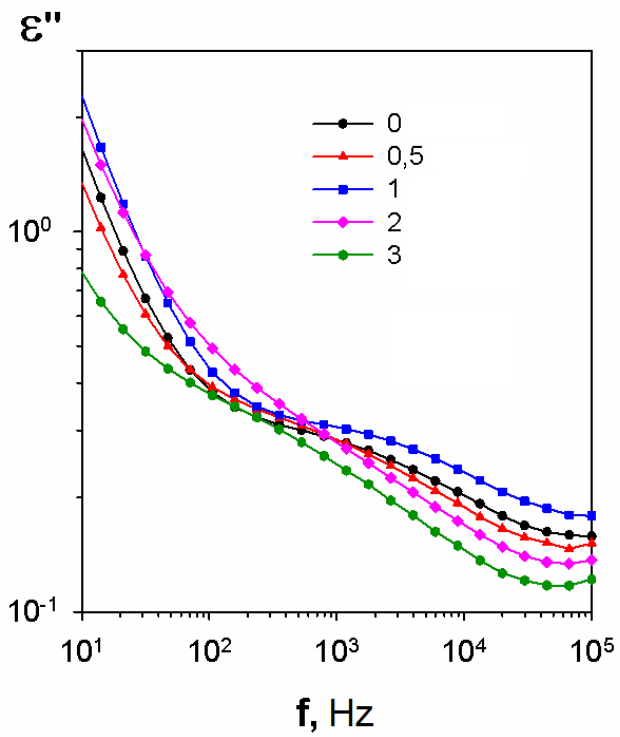

Fig. 3 Dependence of $\varepsilon$ ', on frequency in an EP polymer containing different concentrations of $\mathrm{TiO} 2$ nanoparticles. Measurement temperature $120^{\circ} \mathrm{C}$ 
At high temperatures, measurements of more than $100{ }^{\circ} \mathrm{C}$ at low frequencies on the $\varepsilon(\mathrm{f})$, dependence, in addition to the through conduction, there is a step, which with an increase in the measurement temperature shifts towards higher frequencies (Figure 4).

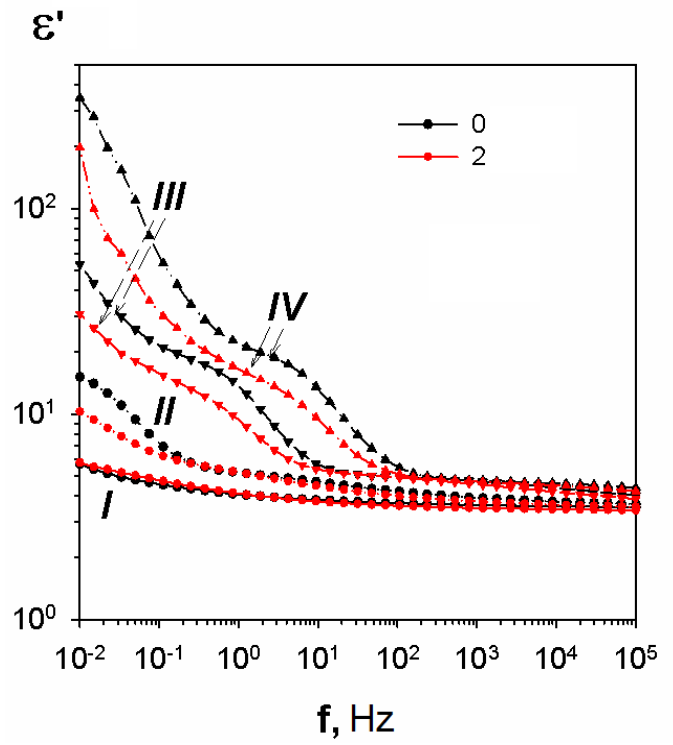

Fig. 4 Dependence of $\varepsilon /$ on frequency in epoxy polymer (black curves) and polymer containing $2 \% \mathrm{TiO} 2$ nanoparticles (red curves) for different temperatures. I - 373; II - 383; III - 403; IV - $423 \mathrm{~K}$.

From the Fig. 4 it can be seen that when nanoparticles are introduced, $\varepsilon$ shifts towards lower frequencies. A weakly pronounced maximum of P3 was also observed in the $\varepsilon$ "' (f) curves.

The image (Figure 5) shows the dependence of the real part $\sigma^{\prime}$ of the complex electrical conductivity $\sigma^{*}=\sigma^{\prime}+j \sigma^{\prime}$.

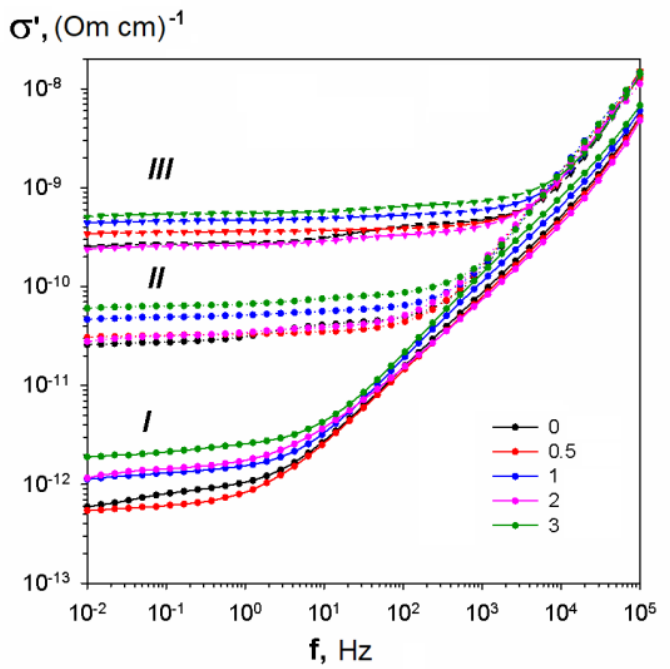

Fig. 5 Dependence of $\sigma$ ' on frequency in an epoxy polymer containing different concentrations of $\mathrm{TiO} 2$ nanoparticles for different temperatures: I - 110; II - 130; III $-150{ }^{\circ} \mathrm{C}$.

It can be seen that a plateau corresponding to the through conduction is observed in the figure at low frequencies. With an increase in the concentration of introduced nanoparticles, the value of the through conduction increases.

Thus, our studies have shown that the introduction of $\mathrm{TiO}_{2}$ nanoparticles into the ED-20 epoxy polymer leads not only to a slowdown in relaxation processes, but also increases the value of the through conduction. According to the position of peak P1 on the temperature axis, it should be attributed to $\beta$ relaxation, peaks $\mathrm{P} 2$ and $\mathrm{P} 3-\alpha$-relaxation.

As it can be seen from the data obtained, the greatest influence of the introduction of nanoparticles on relaxation processes is observed on the $\alpha$ - relaxation. And since $\alpha$ relaxation occurs with the participation of the free volume of the substance, it is natural to assume that the introduction of $\mathrm{TiO}_{2}$ nanoparticles leads to a decrease in the free volume. The presence of a wide peak of $\beta$-relaxation may indicate that a wide range of side groups are involved in relaxation.

\section{CONCLUSION}

Studies of the dielectric properties have shown that the introduction of $\mathrm{TiO}_{2}$ nanoparticles into the ED-20 epoxy polymer slows down the relaxation processes and also increases the through conduction regardless of temperature. The greatest influence on relaxation processes is observed during $\alpha$-relaxation.

This opens new prospective for tailored fabrication of polymer nanocomposites with desired structure and properties. Further research can be aimed toward the development of nanocomposites with advanced mechanical properties.

To determine the structure of the obtained nanocomposite, the method of IR spectroscopy can be further used. IR spectroscopy allows first to get evidences of the interaction between nanoparticles and polymer matrix and, second, get the information about the structure of the resulting nanocomposite.

\section{REFERENCES}

[1] A. V. Babaytsev, E. L. Kuznetsova, L. N. Rabinskiy, O. V. Tushavina, "Investigation of permanent strains in nanomodified composites after molding at elevated temperatures," Periodico Tche Quimica, 17(34), pp. 1055-1067, 2020.

[2] V. N. Dobryanskiy, L. N. Rabinskiy, O. V. Tushavina, "Experimental finding of fracture toughness characteristics and theoretical modeling of crack propagation processes in carbon fiber samples under conditions of additive production", Periodico Tche Quimica, 16(33), pp. 325-336, 2019.

[3] B. A. Antufev, E. L. Kuznetsova, L. N. Rabinskiy, O. V. Tushavina, "Investigation of a complex stress-strain state of a cylindrical shell with a dynamically collapsing internal elastic base under the influence of temperature fields of various physical nature," Asia Life Sciences, (2), pp. 689-696, 2019.

[4] B. A. Antufev, E. L. Kuznetsova, L. N. Rabinskiy, O. V. Tushavina, "Complex stressed deformed state of a cylindrical shell with a dynamically destructive internal elastic base under the action of temperature fields of 
various physical nature," Asia Life Sciences, (2), pp. 775$782,2019$.

[5] L. N. Rabinskiy, O. V. Tushavina, "Problems of land reclamation and heat protection of biological objects against contamination by the aviation and rocket launch site," Journal of Environmental Management and Tourism, 10(5), pp. 967-973, 2019.

[6] V. N. Dobryanskiy, L. N. Rabinskiy, O. V. Tushavina, "Validation of methodology for modeling effects of loss of stability in thin-walled parts manufactured using SLM technology," Periodico Tche Quimica, 16(33), pp. 650656, 2019.

[7] O. A. Pashkov, "Influence of Polymer Coatings on the Mechanical Properties of Steel Samples in Tensile and Bending Tests," Studies in Systems, Decision and Control, to be published.

[8] O. A. Pashkov, "Investigation of the Effect of Steel Plate Size and Elevated Temperature on Critical Load in Stability Tests," Studies in Systems, Decision and Control, to be published.

[9] Y. Sun, O. V. Egorova, E. L. Kuznetsova, "Identification of the front angle of a plane acoustic oblique pressure wave on convex surfaces with the use of analytical solution," Journal of the Balkan Tribological Association, 27(2), pp. 189-197, 2021.

[10]N. A. Bulychev, L. N. Rabinskiy, O. V. Tushavina, "Effect of intense mechanical vibration of ultrasonic frequency on thermal unstable low-temperature plasma," Nanoscience and Technology: An International Journal, 11 (1), pp. 15-21, 2020.

[11]L. N. Rabinskiy, S. A. Sitnikov, "Development of technologies for obtaining composite material based on silicone binder for its further use in space electric rocket engines," Periodico Tche Quimica, 15(Special Issue 1), pp. 390-395, 2018.

[12] M. Sha, Y. A. Utkin, O. V. Tushavina, P. F. Pronina, "Experimental studies of heat and mass transfer from tip models made of carbon-carbon composite material (cccm) under conditions of high-intensity thermal load," Periodico Tche Quimica, vol.17, i. 35, pp. 988-997, 2020.

[13] O. A. Pashkov, "Theoretical calculation of the thickness of interphase zones in the Al-Al2O3 composite," Studies in Systems, Decision and Control, to be published.

[14] O. A. Pashkov, "Experimental and Theoretical Study of Mechanical Properties of Matrix Composite Materials," Studies in Systems, Decision and Control, to be published.

[15] P. F. Pronina, O. V. Tushavina, E. I. Starovoitov, "Study of the radiation situation in moscow by investigating elastoplastic bodies in a neutron flux taking into account thermal effects," Periodico Tche Quimica, 17(35), pp. 753-764, 2020.

[16] O. V. Tushavina, "Coupled heat transfer between a viscous shock gasdynamic layer and a transversely streamlined anisotropic half-space," INCAS Bulletin, 12 (Special Issue), pp. 211-220, 2020.

[17] Y. K. Kyaw, E. L. Kuznetsova, A. V. Makarenko "Complex mathematical modelling of mechatronic modules of promising mobile objects," INCAS Bulletin, 12(Special Issue), pp. 91-98, 2020.

[18]Y. K. Kyaw, P. F. Pronina, P. O. Polyakov, "Mathematical modelling of the effect of heat fluxes from external sources on the surface of spacecraft," Journal of Applied Engineering Science, 18(4), pp. 732-736, 2020.

[19]O. A. Butusova, "Surface Modification of Titanium Dioxide Microparticles Under Ultrasonic Treatment," International Journal of Pharmaceutical Research, vol. 12, i. 4, pp. 2292-2296, 2020.

[20] O. A. Butusova, "Stabilization of Carbon Microparticles by High-Molecular Surfactants," International Journal of Pharmaceutical Research, vol. 12, Supplementary Issue 2, pp. 1147-1151, 2020.

[21] Yu. V. Ioni, A. Ethiraj, "New Tailor-Made Polymer Stabilizers for Aqueous Dispersions of Hydrophobic Carbon Nanoparticles," International Journal of Pharmaceutical Research, vol. 12, i. 4, pp. 3443-3446, 2020.

[22] Yu. V. Ioni, "Nanoparticles of noble metals on the surface of graphene flakes," Periodico Tche Quimica, vol. 17, no. 36, pp. 1199-1211, 2020.

[23] O. A. Butusova, "Vinyl Ether Copolymers as Stabilizers of Carbon Black Suspensions," International Journal of Pharmaceutical Research, vol. 12, Supplementary Issue 2, pp. 1152-1155, 2020.

[24] M. O. Kaptakov, "Catalytic Desulfuration of Oil Products under Ultrasonic Treatment," International Journal of Pharmaceutical Research, vol. 12, Supplementary Issue 2, pp. 1838-1843, 2020.

[25]B. A. Garibyan, "Enhancement of Mechanical Properties of Inorganic Glass under Ultrasonic Treatment," International Journal of Pharmaceutical Research, vol. 12, Supplementary Issue 2, pp. 1829-1832, 2020.

[26]M. O. Kaptakov, "Enhancement of Quality of Oil Products under Ultrasonic Treatment," International Journal of Pharmaceutical Research, vol. 12, Supplementary Issue 2, pp. 1851-1855, 2020.

[27]O. A. Butusova, "Adsorption Behaviour of Ethylhydroxyethyl Cellulose on the Surface of Microparticles of Titanium and Ferrous Oxides," International Journal of Pharmaceutical Research, vol. 12, Supplementary Issue 2, pp. 1156-1159, 2020.

[28] A. N. Tarasova, "Vibration-based Method for Mechanochemical Coating Metallic Surfaces," International Journal of Pharmaceutical Research, vol. 12, Supplementary Issue 2, pp. 1160-1168, 2020.

[29]B. A. Garibyan, "Mechanical Properties of Electroconductive Ceramics," International Journal of Pharmaceutical Research, vol. 12, Supplementary Issue 2, pp. 1825-1828, 2020.

[30]M. O. Kaptakov, "Effect of Ultrasonic Treatment on Stability of $\mathrm{TiO}_{2}$ Aqueous Dispersions in Presence of Water-Soluble Polymers," International Journal of Pharmaceutical Research, vol. 12, Supplementary Issue 2, pp. 1821-1824, 2020.

[31] Yu. V. Ioni, "Synthesis of Metal Oxide Nanoparticles and Formation of Nanostructured Layers on Surfaces under 
Ultrasonic Vibrations," International Journal of Pharmaceutical Research, vol. 12, i. 4, pp. 3432-3435, 2020.

[32] A. N. Tarasova, "Effect of Reagent Concentrations on Equilibria in Water-Soluble Complexes," International Journal of Pharmaceutical Research, vol. 12, Supplementary Issue 2, pp. 1169-1172, 2020.

[33]A. N. Tarasova, "Effect of Vibration on Physical Properties of Polymeric Latexes," International Journal of Pharmaceutical Research, vol. 12, Supplementary Issue 2, pp. 1173-1180, 2020.

[34] Yu. V. Ioni, A. Ethiraj, "Study of Microparticles Surface Modification by Electrokinetic Potential Measuring," International Journal of Pharmaceutical Research, vol. 12, i. 4, pp. 3436-3439, 2020.

[35] Yu. V. Ioni, "Effect of Ultrasonic Treatment on Properties of Aqueous Dispersions of Inorganic and Organic Particles in Presence of Water-Soluble Polymers," International Journal of Pharmaceutical Research, vol. 12, i. 4, pp. 3440-3442, 2020.

[36] L. N. Rabinskiy, O. V. Tushavina, V. F. Formalev, "Mathematical modeling of heat and mass transfer in shock layer on dimmed bodies at aerodynamic heating of aircraft," Asia Life Sciences, (2), pp. 897-911, 2019.

[37] O. A. Butusova, "Chemical and Physical Properties of Magnetic Composite Materials," Studies in Systems, Decision and Control, to be published.

[38] O. A. Butusova, "Investigation of Adsorption Capacity of Magnetic Sorbents for Medical Application," Studies in Systems, Decision and Control, to be published.

[39] L. N. Rabinskiy, O. V. Tushavina, E. I. Starovoitov, "Study of thermal effects of electromagnetic radiation on the environment from space rocket activity," INCAS Bulletin, 12 (Special Issue), pp. 141-148, 2020.

[40] N. V. Britvin, E. O. Karpukhin, "Determining the linear network code parameters to minimize the destructive factors influence in telecommunications systems and networks," Journal of Physics: Conference Series, vol. 1889, no. 3, 032016, 2021.

[41] S. V. Grazion, M. V. Mukomela, M. N. Erofeev, V. V. Spiryagin, S. S. Amelin, "Experimental Estimation of the Waveguide Effect on the Acoustic Emission Signal Parameters in Monitoring Facilities with a Long Surface Radius of Curvature," Journal of Machinery Manufacture and Reliability, vol. 49, no. 11, pp. 971-979, 2020.

[42] M. I. Gordeeva, "Methods for forecasting and control of the phase composition and residual voltage in $\mathrm{Al}-\mathrm{Cu}-\mathrm{Li}$ alloys in friction mixing welding" Journal of Physics: Conference Series, vol. 1713, no. 1, 012017, 2020.

[43] V. F. Formalev, S. A. Kolesnik, E. L. Kuznetsova, "Analytical study on heat transfer in anisotropic space with thermal conductivity tensor components depending on temperature," Periodico Tche Quimica, 15(Special Issue 1), pp. 426-432, 2018.

[44]N. A. Kucheva, V. Kohlert, "Mathematical modeling methods for estimation the thermophysical properties of heat-protective composite materials," Studies in Systems, Decision and Control, to be published.
[45]N. A. Kucheva, "Investigation of the mechanical properties of heat-protective highly porous composite materials using the effective medium model," Studies in Systems, Decision and Control, to be published.

[46] N. A. Kucheva, V. Kohlert, "Analytical solution of the problem of thermoelasticity for a plate heated by a source with a constant heat supply on one surface," Studies in Systems, Decision and Control, to be published.

[47] V. F. Formalev, S. A. Kolesnik, "Temperature-dependent anisotropic bodies thermal conductivity tensor components identification method," International Journal of Heat and Mass Transfer, 123, pp. 994-998, 2018.

[48] S. A. Kolesnik, N. A. Bulychev, "Numerical analytic method for solving the inverse coefficient problem of heat conduction in anisotropic half-space," Journal of Physics: Conference Series, 1474(1), 012024, 2020.

[49] N. A. Bulychev, A. V. Ivanov, "Effect of vibration on structure and properties of polymeric membranes," International Journal of Nanotechnology, vol. 16, nos. 6/7/8/9/10, pp. $334-343,2019$.

[50] A. V. Perchenok, E. V. Suvorova, A. A. Farmakovskaya, V. Kohlert, "Application of vinyl ether copolymers for surface modification of carbon black," International Journal of Circuits, Systems and Signal Processing, vol. 15, pp. , 2021.

[51] A. V. Perchenok, E. V. Suvorova, A. A. Farmakovskaya, V. Kohlert, "Stabilization of aqueous dispersions of inorganic microparticles under mechanical activation," WSEAS Transactions on Applied and Theoretical Mechanics, vol. 16, pp. , 2021.

[52] N. A. Bulychev, A. V. Ivanov, "Nanostructure of OrganicInorganic Composite Materials Based on Polymer Hydrogels," International Journal of Nanotechnology, vol. 16, nos. 6/7/8/9/10, pp. $344-355,2019$.

[53] N. A. Bulychev, A. V. Ivanov, "Study of Nanostructure of Polymer Adsorption Layers on the Particles Surface of Titanium Dioxide," International Journal of Nanotechnology, vol. 16, nos. 6/7/8/9/10, pp. $356-365$, 2019.

[54]N. A. Bulychev, L. N. Rabinskiy, O. V. Tushavina, "Effect of intense mechanical vibration of ultrasonic frequency on thermal unstable low-temperature plasma," Nanoscience and Technology: An International Journal, 11 (1), pp. 15-21, 2020.

[55]N. A. Bulychev, L. N. Rabinskiy, "Ceramic Nanostructures Obtained by Acoustoplasma Technique," Nanoscience and Technology: An International Journal, 10 (3), pp. 279-286, 2019.

[56] V. F. Formalev, S. A. Kolesnik, E. L. Kuznetsova, "Analytical solution-based study of the nonstationary thermal state of anisotropic composite materials," Composites: Mechanics, Computations, Applications, 9(3), pp. 223-237, 2018.

[57] V. F. Formalev, S. A. Kolesnik, "On Thermal Solitons during Wave Heat Transfer in Restricted Areas," High Temperature, 57(4), pp. 498-502, 2019.

[58] V. F. Formalev, S. A. Kolesnik, E. L. Kuznetsova, L. N. Rabinskiy, "Origination and propagation of temperature 
solitons with wave heat transfer in the bounded area during additive technological processes," Periodico Tche Quimica, 16(33), pp. 505-515, 2019.

[59] V. F. Formalev, S. A. Kolesnik, E. L. Kuznetsova, "Mathematical modeling of a new method of thermal protection based on the injection of special coolants," Periodico Tche Quimica, 16(32), pp. 598-607, 2019.

[60]M. O. Kaptakov, "Enhancement of Physical and Mechanical Properties of Metal Surfaces Coated by Polymers," Studies in Systems, Decision and Control, to be published.

[61]B. A. Garibyan, "Determination of the Elastic Modulus of the Coating Using a Spherical Indenter," Studies in Systems, Decision and Control, to be published.

[62] M. O. Kaptakov, "Calculation of Physical and Mechanical Parameters of Metal Samples with Polymer Layers," Studies in Systems, Decision and Control, to be published.

[63] B. A. Garibyan, "Theoretical Estimations of Influence of Polymer Coatings on the Elastic Modulus and Ultimate Strength of Steel Samples," Studies in Systems, Decision and Control, to be published.

[64] M. O. Kaptakov, "Numerical and Analytical Study of Mechanical Characteristics of Nanocomposites Based on Carbon Additives," Studies in Systems, Decision and Control, to be published.

[65]M. O. Kaptakov, "Synthesis and Investigation of Composite Materials Reinforced with Carbon Wires," Studies in Systems, Decision and Control, to be published.

[66] V. F. Formalev, S. A. Kolesnik, "On Inverse Coefficient Heat-Conduction Problems on Reconstruction of Nonlinear Components of the Thermal-Conductivity Tensor of Anisotropic Bodies," Journal of Engineering Physics and Thermophysics, 90(6), pp. 1302-1309, 2017.

[67] V. F. Formalev, S. A. Kolesnik, "Analytical investigation of heat transfer in an anisotropic band with heat fluxes assigned at the boundaries," Journal of Engineering Physics and Thermophysics, 89(4), pp. 975-984, 2016.

[68] V. F. Formalev, E. M. Kartashov, S. A. Kolesnik, "Simulation of Nonequilibrium Heat Transfer in an Anisotropic Semispace Under the Action of a Point Heat Source," Journal of Engineering Physics and Thermophysics, 92(6), pp. 1537-1547, 2019.

[69]I. S. Kurchatov, N. A. Bulychev, S. A. Kolesnik, "Obtaining Spectral Characteristics of Semiconductors of AIIBVI Type Alloyed with Iron Ions Using Direct Matrix Analysis," International Journal of Recent Technology and Engineering, vol. 8, i. 3, pp. 8328-8330, 2019.

[70] V. F. Formalev, S. A. Kolesnik, E. L. Kuznetsova, "Identification of new law for decomposition of bonding heat-shielding composite materials," Asia Life Sciences, (1), pp. 139-148, 2019.

[71]E. L. Kuznetsova, A. V. Makarenko, "Mathematical model of energy efficiency of mechatronic modules and power sources for prospective mobile objects," Periodico Tche Quimica, 16 (32), pp. 529-541, 2019.

[72] L. N. Rabinskiy, E. L. Kuznetsova, "Analytical and numerical study of heat and mass transfer in composite materials on the basis of the solution of a stefan-type problem," Periodico Tche Quimica, 15 (Special Issue 1), pp. 339-347, 2018.

[73]N. A. Bulychev, E. L. Kuznetsova, "Ultrasonic Application of Nanostructured Coatings on Metals," Russian Engineering Research, 39 (9), pp. 809-812, 2019.

[74]N. A. Bulychev, V. V. Bodryshev, L. N. Rabinskiy, "Analysis of geometric characteristics of two-phase polymer-solvent systems during the separation of solutions according to the intensity of the image of micrographs," Periodico Tche Quimica, 16(32), pp. 551$559,2019$.

[75]L. N. Rabinskii, O. V. Tushavina, "Composite Heat Shields in Intense Energy Fluxes with Diffusion," Russian Engineering Research, 39(9), pp. 800-803, 2019.

[76] L. N. Rabinskiy, O. V. Tushavina, "Investigation of the influence of thermal and climate effects on the performance of tiled thermal protection of spacecraft," Periodico Tche Quimica, 16(33), pp. 657-667, 2019.

[77] V. V. Bodryshev, L. N. Rabinskiy, L. G. Nartova, N. P. Korzhov, "Geometry analysis of supersonic flow around two axially symmetrical bodies using the digital image processing method," Periódico Tchê Química, vol. 16, no. 33, pp. 541-548, 2019.

[78] N. A. Bulychev, M. A. Kazaryan, A. I. Erokhin, A. S. Averyushkin, L. N. Rabinskii, V. V. Bodryshev, B. A. Garibyan, "Analysis of the Structure of the Adsorbed Polymer Layers on the Surfaces of Russian Metallurgy (Metally)," vol. 2019, no. 13, pp. 1319-1325.

\section{Contribution of Individual Authors to the Creation of a Scientific Article (Ghostwriting Policy)}

A. Getmanov synthesized the nanocomposites.

Tran Quyet Thang studied the properties of nanocomposites.

\section{Creative Commons Attribution License 4.0 (Attribution 4.0 International, CC BY 4.0)}

This article is published under the terms of the Creative Commons Attribution License 4.0

https://creativecommons.org/licenses/by/4.0/deed.en_US 